\title{
State-Uncertainty preferences and the Risk Premium in the Exchange rate market ${ }^{\#}$
}

\author{
Juan-Angel Jimenez-Martin ${ }^{\mathrm{a}} \quad$ Alfonso Novales Cinca ${ }^{\mathrm{b} *}$ \\ a Dpto. de Fundamentos de Análisis Económico II, Universidad Complutense. \\ b Dpto. de Fundamentos de Análisis Económico II, Universidad Complutense.
}

\begin{abstract}
:
This paper introduces state-uncertainty preferences into the Lucas (1982) economy, showing that this type of preferences helps to explain the exchange rate risk premium. Under these preferences we can distinguish between two factors driving the exchange rate risk premium: "macroeconomic risk" and "the risk associated with variation in the private agents' perception on the level of uncertainty". State-uncertainty preferences amount to assuming that a given level of consumption will yield a higher level of utility the lower is the level of uncertainty perceived by consumers. Furthermore, empirical evidence from three main European economies in the transition period to the euro provides empirical support for the model
\end{abstract}

JEL Classification: F31, F41, G12, G15

Keywords: Risk premium, taste shocks, fundamental uncertainty.

* Corresponding author. Tel.: +34 9139423 55. Fax: +34 91394 2613;

E_mail: juanangel@ccee.ucm.es

\#I am grateful to R. Flores, G. Kaminsky, and P. Vega for helpful comments. The paper has benefited from comments from seminar participants at the George Washington University. I would like to acknowledge the financial support of the Ministerio de Educación, Spain, through Project SEJ2006-14354 and the Fundacion Caja Madrid. Parts of this work were completed while visiting George Washington University, Washington, DC. The author is grateful to this institution for its hospitality.

*Corresponding author. Dpto. de Fundamentos de Análisis Económico II, Universidad Complutense, Somosaguas, 28223, Spain. Tel.: +34 91394 2594. Fax: +34 91394 2613. Email: anovales@ccee.ucm.es 


\section{Introduction}

According to the standard uncovered interest rate parity (UIP) condition, the expected change in an exchange rate should be equal to the interest rate differential between foreign and domestic risk-free bonds. Instead, empirical work usually shows that the slope coefficient from the linear projection of the change in the foreign exchange rate on the interest rate differential is significantly negative, which implies that the domestic currency is expected to appreciate when domestic nominal interest rates exceed foreign interest rates. This is puzzling because economic intuition suggests that international investors would demand higher interest rates on currencies expected to fall in value. Among the explanations of this anomaly is that there exists a timevarying risk premium in currency markets.

Attempts to account for the forward premium anomaly (changes in spot exchange rate is inversely related to the premium forward rates over spot rates) by time varying risk premium have mostly focused on exploring dynamic stochastic, general equilibrium representative models with identical consumers endowed with an isoelastic expected utility preferences. Engle (1996) provides an excellent survey of this literature and shows that most of these models are unable to explain the risk premiums observed in actual financial markets. The problem resides in the smoothness of consumption growth, relative to the volatility of the risk premium embedded in asset prices.

Inside the representative agent framework, several authors have attempted to rationalize asset pricing through state-dependent preferences. Examples include papers where it is postulated that the utility produced by a given level of consumption depends on the previous level of consumption (habit formation), (as in Costantinides, 1990 and Campbell and Cochrane, 1999), relative social standing (as in Bakshi and Chen, 1996), or stochastic subsistence consumption levels (Campbell and Viceira, 2001). We take an alternative avenue that considers the perception by consumers on the current level of uncertainty as the state variable in preferences. A given level of consumption would then yield a higher level of utility when the consumer feels relatively certain about his future income stream than in periods when the range of possible income streams is wider. Such belief-dependent preferences are bound to induce real effects from changes in the perception on the level uncertainty through shifts in aggregate demand.

That this effect can improve the explanation of the observed behaviour in currency premium relative to previous specifications is shown here in a model á la Lucas (1982). First order conditions for the time aggregate, expected utility maximization problem under standard 
distributional assumptions lead to an analytical expression that allows us to examine the effect on risk premiums of both, private agents' perception on the level of uncertainty and the volatility of macroeconomic aggregates. This way, we can discuss the relative importance of each type of volatility to explain excess returns in the exchange rate market.

As an illustration, we use the unique experiment provided by the convergence process to a monetary union in Europe. We assume that the "level of uncertainty" is adequately represented by private agent beliefs on the probability of their country entering the Eurozone. Being inside the currency union would suggest higher credibility, with low inflation and increased stability, the opposite being the case in the case the country would not enter the union. Changes in the perceived probability of that event would produce changes in the level of uncertainty on future economic policy, which in turn would lead to changes in the utility (and marginal utility) of consumption.

We proceed as follows. In section two we present the theoretical model and describe the relationships among risk premium, fundamental variables volatility, and the level of uncertainty that are obtained from the Euler condition. We also derive an analytical expression for the risk premium that allows for statistical tests to be performed. As an illustration, in the third section, we apply this model to account for the risk premium during the transition period to the European currency. Section four presents the main conclusions.

\section{2.- Optimal Decisions, the Level of Uncertainty and the Risk Premium}

Fama (1984) defines the foreign exchange risk premium, $R p_{t+1}^{e}$, as the difference between the market expectation of currency depreciation and the current one-period forward premium, $f p_{t}^{t+1}$ :

$$
\mathrm{Rp}_{\mathrm{t}+1}^{\mathrm{e}}=\left[\mathrm{E}_{\mathrm{t}}\left(\mathrm{s}_{\mathrm{t}+1}\right)-\mathrm{s}_{\mathrm{t}}\right]-\mathrm{fp}_{\mathrm{t}}^{\mathrm{t}+1}=\left[\mathrm{E}_{\mathrm{t}}\left(\mathrm{s}_{\mathrm{t}+1}\right)-\mathrm{s}_{\mathrm{t}}\right]-\left[\mathrm{f}_{\mathrm{t}}^{\mathrm{t}+1}-\mathrm{s}_{t}\right]=\mathrm{E}_{\mathrm{t}}\left(\mathrm{s}_{\mathrm{t}+1}\right)-\mathrm{f}_{\mathrm{t}}^{\mathrm{t}+1}
$$

where $s_{t}$ and $f_{t}$ denotes the logarithm of spot and forward rates. The exchange rate risk premium can be interpreted as the excess return of a domestic investor who borrows one unit of domestic currency, buys $1 /$ St worth of foreign currency, lends it on the foreign market for one period, and reconverts his earnings to the domestic currency. 
We look for evidence on the role of private agents' perceptions on the level of uncertainty in explaining the currency market anomaly, in a basic representative agent, consumption-based asset pricing model [Lucas (1982) and Hu (1997)]. The model considers two countries (domestic and foreign) and two perishable commodities. In each country, a different currency is used to pay for transactions in their respective commodities. Each period $t$, the domestic (foreign) country receives a stochastic endowment $Y_{t}^{D}\left(Y_{t}^{\mathrm{F}}\right)$, and zero units of the other commodity. The domestic (foreign) country also receives a stochastic endowment $M_{t}^{D}\left(M_{t}^{F}\right)$ of its own currency.

Consumers are identical in both countries. The model is written from the perspective of the domestic country. The representative consumer maximizes time aggregate expected utility:

$$
\mathrm{U}_{\mathrm{t}}=\mathrm{E}_{\mathrm{t}} \sum_{\mathrm{s}=\mathrm{t}}^{\infty} \beta^{\mathrm{s}-\mathrm{t}} \mathrm{U}\left(\mathrm{c}_{\mathrm{is}}^{\mathrm{D}}, \mathrm{c}_{\mathrm{is}}^{\mathrm{F}}, \mathrm{Z}_{\mathrm{is}}\right) \quad 0<\beta<1
$$

where $E_{t}$ denotes the conditional expectation based on information known at the beginning of period $t . \quad c_{i s}{ }^{D}, c_{i s} F$ represent the consumption levels of the domestic and foreign goods by the representative agent of country $i$ at period $s$, and $Z_{i s}$ denotes the perceived level of uncertainty in country $i$ at time $s^{1}{ }^{1}$ We assume the utility function $U($., .) to be bounded, continuously differentiable, increasing in the consumption of domestic and foreign goods, decreasing in the level of uncertainty, and strictly concave. The cross derivative $U_{C Z}$ can take any sign, and $\beta$ is the constant time discount factor.

The equilibrium exchange rate, in units of domestic currency per unit of foreign currency, is:

$$
S_{t}=\frac{P_{t}^{D}}{P_{t}^{F}} \cdot \frac{U_{c_{D}^{F}}\left(c_{D t}^{D}, c_{D t}^{F}, Z_{i t}\right)}{U_{c_{D}^{D}}\left(c_{D t}^{D}, c_{D t}^{F}, Z_{i t}\right)}
$$

Therefore, we can define the change in the exchange rate as:

$$
\frac{S_{t+1}}{S_{t}}=\frac{q_{t+1}^{F}}{q_{t+1}^{D}} .
$$

Where,

${ }^{1}$ This is in the spirit of alternative formulations of state-dependent preferences, now with a different rationalization of the state variable. In Bakshi and Chen (1996) the state depends on social standing, while Campbell and Cochrane (1999) use state-dependent preferences with habits. 


$$
q_{t+1}^{j}=\beta U_{c_{D}^{j}}\left(c_{D t+1}^{D}, c_{D t+1}^{F}, Z_{i t+1}\right) P_{t+1}^{j} /\left(U_{c_{D}^{j}}\left(c_{D t}^{D}, c_{D t}^{F}, Z_{i t}\right) P_{t}^{i}\right), \text { for } j=D, F
$$

denotes the intertemporal marginal rate of substitution (IMRS).

A forward contract specifies at date $t$ the number of units of domestic currency $\mathrm{F}_{t}^{+1}$ to be exchanged at time $t+1$ for one unit of foreign currency. Forward contracts allow consumers to insure themselves against the uncertainty on the future purchasing power of their own currencies. This contract specifies a net flow of domestic currency at date $t+1$ of $F_{t}^{++1}-\mathrm{S}_{\mathrm{t}+1}$. Since it involves no payments at date $t$, the fair (absence of arbitrage) pricing relationship implies [see Backus et al. (2001)]:

$$
E_{t}\left(q^{D}{ }_{t+1}\left(F_{t}^{t+1}-S_{t+1}\right)\right)=0
$$

Dividing (6) by $S_{t}$ and using (4), $\left(\mathrm{F}_{\mathrm{t}}^{\mathrm{t}+1} / \mathrm{s}_{\mathrm{t}}\right) \mathrm{E}_{\mathrm{t}}\left(\mathrm{q}_{\mathrm{t}+1}^{\mathrm{D}}\right)=\mathrm{E}_{\mathrm{t}}\left(\mathrm{q}_{\mathrm{t}+1}^{\mathrm{D}}\left(\mathrm{S}_{\mathrm{t}+1} / \mathrm{S}_{\mathrm{t}}\right)\right)=\mathrm{E}_{\mathrm{t}}\left(\mathrm{q}_{\mathrm{t}+1}^{\mathrm{F}}\right)$. Therefore, we can obtain the forward premium $\mathrm{fp}_{\mathrm{t}}^{\mathrm{t}+1}$ as the $\log$ of the ratio:

$$
\frac{F_{t}^{t+1}}{S_{t}}=\frac{E_{t}\left(q_{t+1}^{F}\right)}{E_{t}\left(q^{D}{ }_{t+1}\right)}
$$

Thus, given (1), (4) and (7) the risk premium $R p_{t+1}^{e}$ becomes:

$$
\mathrm{RP}_{\mathrm{t}+1}^{\mathrm{e}}=\mathrm{E}_{\mathrm{t}}\left[\log \left(\mathrm{q}_{\mathrm{t}+1}^{\mathrm{F}}\right)\right]-\mathrm{E}_{\mathrm{t}}\left[\log \left(\mathrm{q}_{\mathrm{t}+1}^{\mathrm{D}}\right)\right]-\left\{\log \left(\mathrm{E}_{\mathrm{t}}\left[\mathrm{q}_{\mathrm{t}+1}^{\mathrm{F}}\right]\right)-\log \left(\mathrm{E}_{\mathrm{t}}\left[\mathrm{q}_{\mathrm{t}+1}^{\mathrm{D}}\right]\right)\right\}
$$

That is, $R p_{t+1}^{e}$ is the difference between the "the expectation of the log" and the "log of the expectation" of the IMRS for the foreign and domestic goods. Assuming log-normality of IMRS in (8) (as in Backus et al., 2001, and Alvarez, Atkenson, and Kehoe, 2007), the risk premium is equal to:

$$
\mathrm{RP}_{\mathrm{t}+1}^{\mathrm{e}}=\frac{1}{2} \sigma_{\mathrm{q}_{\mathrm{t}+1}^{\mathrm{D}}}^{2}-\frac{1}{2} \sigma_{\mathrm{q}_{\mathrm{t}+1}^{F}}^{2}
$$


where $\sigma_{q_{t+1}^{i}}^{2}$ denotes the conditional variance of the logarithm of the IMRS for $i=D$, F. Expression (9) shows that a currency risk premium will arise only under significantly different volatility on the inflation-adjusted growth of marginal utility across countries. ${ }^{2}$

Traditional preferences are generally incapable of delivering enough volatility in consumption to explain the empirically observed risk premium, but state-dependent preferences may be able do so. In particular, preferences dependent on the general level of uncertainty can deliver a significant and time-varying currency risk even if the fundamental shocks have low variance. To analytically illustrate the link between the level of uncertainty and the risk premium, we need to impose some additional assumptions on the joint stochastic properties of real and nominal endowments, the probability distribution of the state variable, and the utility function.

\section{1.- Preferences}

We assume the utility function to be time separable as well as separable in the consumption of domestic and foreign goods:

$$
\mathrm{U}\left(\mathrm{c}_{\mathrm{it}}^{\mathrm{D}}, \mathrm{c}_{\mathrm{it}}^{\mathrm{F}}\right)=\frac{\left(\mathrm{c}_{\mathrm{it}}^{\mathrm{D}}\right)^{1-\alpha}}{1-\alpha} \mathrm{Z}_{\mathrm{t}}^{\lambda^{\mathrm{D}}}+\frac{\left(\mathrm{c}_{\mathrm{it}}^{\mathrm{F}}\right)^{1-\gamma}}{1-\gamma} Z_{\mathrm{t}}^{\lambda^{\mathrm{F}}} \quad \alpha, \gamma \geq 0, \lambda^{\mathrm{D}}, \lambda^{\mathrm{F}} \leq 0 \quad \text { and } \alpha \neq 1, \gamma \neq 1 \text {, }
$$

where $\alpha$ and $\gamma$ are risk aversion parameters, $Z_{t}$ is the state variable measuring the perceived level of uncertainty, and $\lambda^{j}$, for $j=D, F$, indicates the extent to which uncertainty affects the utility of the consumption of domestic and foreign goods. Additionally, it is necessary to make some assumptions on the joint stochastic behavior of real and nominal endowments, as well as on the probability distribution of the level of uncertainty before obtaining a tractable expression for the risk premium.

\section{2.- An analytical expression for the risk premium}

If we impose standard cash-in-advance constraints and exploit the conditions for the perfectly pooled equilibrium in Lucas (1982) that consumption is equal in each country to half of

\footnotetext{
2 The intuition of this result goes as follows: The exchange rate risk premium can be written, $R P_{t+1}=E_{t}\left(s_{t+1}-s_{t}\right)$ $\log E_{t}\left(q_{t+1}^{F_{t+1}}\right)+\log E_{t}\left(q^{D} D_{t+1}\right)=E_{t}\left(s_{t+1}-s_{t}\right)+r_{t} r_{t} D_{t}$, where $r t=-\log E_{t}\left(q^{i}{ }_{t+1}\right)=-E_{t} \log \left(q_{t+1}^{i}\right)-1 / 2 \sigma_{q_{t+1}^{i}}$. Thus, given (4), the expected change in the exchange rate is $E_{t}\left(s_{t+1}-s_{t}\right)=E_{t} \log \left(q_{t+1}^{\mathrm{F}}\right)-E_{t} \log \left(q_{t+1}^{D_{t+1}}\right)=-r_{t}^{\mathrm{F}}+r^{D_{t}}-1 / 2 \sigma_{\mathrm{q}_{\mathrm{t}+1}^{\mathrm{F}}}+1 / 2 \sigma_{\mathrm{q}_{\mathrm{t}+1}^{\mathrm{D}}}$. Higher conditional volatility for the domestic IMRS than for the foreign IMRS, would lead to expectations of exchange rate depreciation. Then, the domestic investor would expect a positive foreign currency excess return to compensate $\mathrm{him} / \mathrm{her}$ for the expected loss when his/her assets are abroad.
} 
the domestic and foreign production, the domestic and foreign IMRS from (5) under our assumed preferences, become:

$$
\begin{gathered}
q_{t+1}^{F}=\left(y_{t+1}^{F}\right)^{(1-\gamma)}\left(m_{t+1}^{F}\right)^{-1} z_{t+1}^{\lambda^{F}} \\
q_{t+1}^{D}=\left(y_{t+1}^{D}\right)^{(1-\alpha)}\left(m_{t+1}^{D}\right)^{-1} z_{t+1}^{\lambda^{D}},
\end{gathered}
$$

where $y_{t+1}^{i} \equiv Y_{t+1}^{i} / Y_{t}^{i}, m_{t+1}^{i} \equiv M_{t+1}^{i} / M_{t}^{i}$, for $i=D, F$ and $Z_{t+1} \equiv Z_{t+1} / Z_{t}$.

Expression (3) shows the influence of an increase in uncertainty on the spot exchange rate through price effects and changes in the marginal utilities of domestic and foreign commodities. However, under our structural specification (along with cash-in-advance constraints and pooled equilibrium), the spot exchange rate is given by,

$$
S_{t}=2^{\alpha-\beta} M_{t}^{D}\left(Y_{t}^{F}\right)^{1-\gamma}\left(M_{t}^{F}\right)^{-1}\left(Y_{t}^{D}\right)^{-(1-\alpha)} Z_{t}^{\lambda^{F}-\lambda^{D}}
$$

So that, so long as $\left|\lambda^{\mathrm{D}}\right|>\left|\lambda^{\mathrm{F}}\right|$, an increase in uncertainty will raise the spot exchange rate, depreciating the domestic currency. When $\left|\lambda^{\mathrm{D}}\right|>\left|\lambda^{\mathrm{F}}\right|$ an increase in uncertainty will decrease the marginal utility on domestic goods more than on foreign goods, which in turn leads to a lower demand for domestic goods, and thereby increasing the relative price of foreign good. Hence, the spot exchange rate increases, depreciating the domestic currency.

Additionally, from (11), $\sigma_{q_{t+1}^{i}}=\sigma_{m_{t+1}^{i}}+(1-\alpha)^{2} \sigma_{y_{t+1}^{i}}-2(1-\alpha) \sigma_{y_{t+1}^{i} m_{t+1}^{i}}+\left(\lambda^{i}\right)^{2} \sigma_{z_{t+1}^{i}}^{2}$ for $i=D, F$. The effect on IMRS volatility of a rise in the level of uncertainty, $\sigma_{z_{t+1}^{i}}^{2}$, depends on $\lambda^{j}$. For instance, if $\left|\lambda^{\mathrm{D}}\right|>\left|\lambda^{\mathrm{F}}\right|$, an increase in $\sigma_{z_{t+1}^{i}}^{2}$ has a larger effect on the domestic IMRS than on the foreign IMRS. As shown in footnote 2, this would increase the expected rate of depreciation which, in turn, will lead to an increase in the risk premium.

To have a well defined probability distribution for $q^{F}$ and $q^{D}$, we need to add some structure on the stochastic behavior of the main variables in the model. That will also allow us to relate the risk premium to the main sources of uncertainty in the economy. More precisely, we assume growth in output and money supply and the change in perceived uncertainty to be conditionally jointly log-normal. Following $\mathrm{Hu}$ (1997), we assume that stochastic discount factors are log-normal. 
Thus, from (9) and (11), the risk premium can be written in terms of statistical moments of output growth, monetary aggregates, and the indicator on the level of uncertainty:

$$
\begin{aligned}
\mathrm{RP}_{\mathrm{t}+1}^{\mathrm{e}}= & -\frac{1}{2} \sigma_{\mathrm{m}_{\mathrm{t}+1}^{\mathrm{F}}}^{2}+\frac{1}{2} \sigma_{\mathrm{m}_{\mathrm{t}+1}^{\mathrm{D}}}^{2}-\frac{1}{2}(1-\gamma)^{2} \sigma_{\mathrm{y}_{\mathrm{t}+1}^{\mathrm{F}}}^{2}+\frac{1}{2}(1-\alpha)^{2} \sigma_{\mathrm{y}_{\mathrm{t}+1}^{\mathrm{D}}}^{2}+ \\
& +\frac{1}{2}\left(\left(\lambda^{\mathrm{D}}\right)^{2}-\left(\lambda^{\mathrm{F}}\right)^{2}\right) \sigma_{z_{\mathrm{t}+1}}^{2}+(1-\gamma) \sigma_{\mathrm{y}_{\mathrm{t}+1}^{\mathrm{F}} \mathrm{m}_{\mathrm{t}+1}^{\mathrm{F}}}-(1-\alpha) \sigma_{\mathrm{y}_{\mathrm{t}+1}^{\mathrm{D}} \mathrm{m}_{\mathrm{t}+1}^{\mathrm{D}}}+ \\
& +\lambda^{\mathrm{F}} \sigma_{z_{\mathrm{t}+1} \mathrm{~m}_{\mathrm{t}+1}^{\mathrm{F}}}-\lambda^{\mathrm{D}} \sigma_{z_{\mathrm{t}+1} \mathrm{~m}_{\mathrm{t}+1}^{\mathrm{D}}}-(1-\gamma) \lambda^{\mathrm{F}} \sigma_{z_{\mathrm{t}+1} \mathrm{Y}_{\mathrm{t}+1}^{\mathrm{F}}}+(1-\alpha) \lambda^{\mathrm{D}} \sigma_{z_{\mathrm{t}+1} \mathrm{y}_{\mathrm{t}+1}^{\mathrm{D}}} .
\end{aligned}
$$

where $\sigma_{\mathrm{x}_{\mathrm{t}+1}^{\mathrm{i}}} \equiv \operatorname{var}_{\mathrm{t}}\left(\log \left(\mathrm{x}_{\mathrm{t}+1}^{\mathrm{i}}\right)\right)$ and $\sigma_{\mathrm{x}_{\mathrm{t}+1}^{\mathrm{i}} \mathrm{P}_{\mathrm{t}+1}^{\mathrm{i}}} \equiv \operatorname{cov}_{\mathrm{t}}\left(\log \left(\mathrm{x}_{\mathrm{t}+1}^{\mathrm{i}}\right) \log \left(\mathrm{p}_{\mathrm{t}+1}^{\mathrm{i}}\right)\right)$.

Equation (12) states that expected risk premium is determined by (i) the conditional variance of domestic and foreign output, (ii) the conditional variance of domestic and foreign money supply, (iii) the conditional covariance between output and money supply, ${ }^{3}$ (iv) the conditional variance of the uncertainty indicator, and (v) the conditional covariance between money supply and output with the uncertainty indicator. Conditions i), ii), and iii) are related to macroeconomic uncertainty, while iv) is associated to the nature of the uncertainty indicator.

This model generalizes $\mathrm{Hu}$ (1997) with the exchange rate risk premium having a second source of risk associated to the private agents' perception on the level of uncertainty. This additional argument might provide the additional volatility needed to reproduce the empirically observed high currency risk premium without requiring unreasonable coefficients of relative risk aversion.

In the next section we test whether the proposed model can account for the observed risk premium during the transition period to the European currency using bilateral exchange rates between the French franc, British pound, and Spanish peseta, all relative to the German mark. In this case, fundamental macroeconomic uncertainty, by itself, does not generate sufficient risk to reconcile the traditional model with the data. Forces other than those emerging from macroeconomic indicators seem to be the most important sources of uncertainty in these

\footnotetext{
3 i), ii), and iii) can be explained through their contribution to the volatility of the purchasing power parity of both currencies given the cash in advance constraints. An increase in the volatility of nominal or real income in the domestic country, or a decrease in their covariance, increases the volatility of the purchasing power of the domestic currency, which in turn leads to an increase on the volatility of the domestic IRMS. An increase in the volatility of nominal or real income for the foreign country or a decrease in their joint covariance would lead to the opposite effect on the risk premium.
} 
transition countries. A model with uncertainty-dependent preferences may offer a potential explanation for these other disturbances driving the foreign exchange market.

\section{Testing the Model}

We start the empirical analysis of model (12) by ${ }^{4}$ constructing the indicator that reflects the perception of uncertainty by private agents and by estimating the conditional variances and covariances for the exogenous variables. Then, we estimate (12) by least squares and validate the model through a battery of specification tests. We include a constant term in the model to capture the possibility of second order conditional moments that might not change over time. Since fundamental variables are measured differently in each country, their volatilities are not directly comparable and it is not possible to estimate the model under the constraints imposed by international symmetry. Hence, we only estimate the unrestricted version of the model and test for the existence of risk premia by testing the significance of estimated parameters.

\subsection{An uncertainty indicator}

The main difficulty in estimating the exchange risk premium expression is that the level of uncertainty is unobserved, and a popular approach to dealing with this problem is to postulate a specific law of motion for changes in the level of uncertainty. In our model, $Z_{t}$ represents the type of uncertainty which is not already captured by macroeconomic aggregates as industrial production or money supply. In what follows, we identify $Z_{t}$ with the level of uncertainty on private agents' beliefs on the success or failure of the convergence process to the euro. Additionally, it is natural to assume that the effect of unexpected news depends on the level of uncertainty in the economy. In an economy where agents are almost sure that they will enter the Eurozone, a piece of negative news will have some minor impact. The same could be said about a piece of positive news impinging on an economy where private agents are almost sure that they will not join the euro area. If, on the other, hand, private agents have 50-50 odds that they might

\footnotetext{
${ }^{4}$ We consider the bilateral relationships between Spanish peseta (SPA), Deutsche mark (DEM), Sterling pound (GBP) and French franc (FRF). The sample starts on January 1, 1986 after Spain became a member of the European Economic Community and ends in April 1998 (In May 1998 the European Council announced the countries that would form the euro area on January 1, 1999). We use monthly data for Spain (SP), Germany (GER), France (FR) and United Kingdom (UK). The industrial production index (IP) is used as an indicator of economic activity and M2 as the monetary aggregate. To compute probabilities of convergence, we use interest rates on 3-year maturity swaps for all countries, from 1992:1 to 1998:04. Finally, spot and forward exchange rates are taken for the last day of the month. Preliminary data analysis (unit root tests and intervention analysis [Box and Tiao (1975)]) shows that all variables, except the risk premium, are I(1). Therefore, all variables are differenced in the model for the conditional variance. These preliminary results are not reported here but are available upon request.
} 
joint the euro, then any piece of negative or positive news may have a large contribution to the general level of uncertainty.

We formalize this view by considering a regime indicator $x$, to be realized at time $T$, when the decision of joining the Eurozone is to be made. At that time, $x$ would take a value of 1 if the economy enters the euro system, being equal to 0 otherwise. At each point in time, the representative agent in the economy associates a probability $p_{t}$ of joining the euro area, i.e., to the event $x=1$, and a probability of $\left(1-p_{t}\right)$ of being left out, i.e., to the event $x=0$. The probability $p_{t}$ should be expected to change over time as a function of the information that private agents receive on some economic indicators that agents consider relevant when predicting future policy decisions. Hence, at time $t$, the expected value of $x$ is: $E_{t}(x)=p_{t}$, and its variance: $\left(\sigma_{t}^{x}\right)^{2}=\operatorname{Var}_{t}(x)=p_{t}\left(1-p_{t}\right)$. The variance of $x$ indicates the level of uncertainty on the event of entering the Eurozone.

To capture the suggestion we made above on the fact that the impact of a given piece of news will be larger the higher the level of uncertainty prevailing in the economy, we assume that changes in the level of uncertainty, $z_{t}$, are driven by:

$$
z_{t+1}=\sigma_{t}^{\times} \xi_{t+1}, \quad \xi_{t+1} / p_{t}, p_{t-1}, p_{t-2}, \ldots \sim N(0, \kappa)
$$

where $\xi_{t}$ represents the arrival of new information regarding the fulfillment of Maastricht criteria. The variance of $z_{t+1}$, an indicator of the expected size of changes in uncertainty, is:

$$
\operatorname{var}\left(z_{t+1}\right)=\kappa\left(\sigma_{t}^{x}\right)^{2}=\kappa p_{t}\left(1-p_{t}\right)
$$

Therefore, the variance of $z_{t+1}$ is zero when $p_{t}$ is either 0 or 1 , reflecting absolute certainty about being OUT or IN, a situation of zero euro-uncertainty. The variance of changes in uncertainty reaches its maximum value for intermediate values of $p_{t}$. Whenever $p_{t}<1 / 2$, an increase in the probability of entering the Eurozone will increase the level of uncertainty, whereas, for $p_{t}>1 / 2$, an increase in the probability of joining the euro would reduce the variance of $z_{t+1}$, and the opposite would arise for reductions in $p_{t}$.

Under this specification, adding the assumption that money supply and production are conditionally independent of the level of uncertainty, $Z$, equation (12) can be written: 


$$
\begin{aligned}
\mathrm{RP}_{\mathrm{t}+1}^{\mathrm{e}} & =\lambda \mathrm{p}_{\mathrm{t}}\left(1-\mathrm{p}_{\mathrm{t}}\right)-\frac{1}{2} \sigma_{\mathrm{m}_{\mathrm{t}+1}^{\mathrm{F}}}^{2}+\frac{1}{2} \sigma_{\mathrm{m}_{\mathrm{t}+1}^{\mathrm{D}}}^{2}-\frac{1}{2}(1-\gamma)^{2} \sigma_{\mathrm{y}_{\mathrm{t}+1}^{\mathrm{F}}}^{2}+\frac{1}{2}(1-\alpha)^{2} \sigma_{\mathrm{y}_{\mathrm{t}+1}^{\mathrm{D}}}^{2}+ \\
& +(1-\gamma) \sigma_{\mathrm{y}_{\mathrm{t}+1}^{\mathrm{F}} \mathrm{m}_{\mathrm{t}+1}^{\mathrm{F}}}-(1-\alpha) \sigma_{\mathrm{y}_{\mathrm{t}+1}^{\mathrm{D}} \mathrm{m}_{\mathrm{t}+1}^{\mathrm{D}}}
\end{aligned}
$$

with: $\lambda=\frac{1}{2}\left(\left(\lambda^{D}\right)^{2}-\left(\lambda^{F}\right)^{2}\right) \kappa$.

\subsection{Measuring unobserved variables}

The exchange rate risk premium in (15) depends on the perceived probability of convergence. To substitute for the unobserved probability assigned by the financial markets to the event that the country may belong to the euro area by January 1999, we use a procedure similar to the JP Morgan EMU calculator (J.P. Morgan, 1997). ${ }^{5}$ The basic feature of such a calculator is that the observed interest rate spread at time $t, I R \_S P R$, is supposed to be a weighted average of the $I N$ spread, IR_SPR ${ }^{I N}$, which would apply if the country adopts the single currency and the OUT spread, IR_SPR ${ }^{O U T}$, corresponding to the case when the country is out of the Eurozone. The weights are the corresponding probabilities for each event,

$$
I R \_S P R=p_{t} I R \_S P R R_{t}^{I N}+\left(1-p_{t}\right) I R \_S P R R_{t}^{\text {OUT }}
$$

In a monetary union, financial instruments from different countries sharing the same maturity, liquidity and credit risk must have the same yield. Hence, if a country fulfills the convergence criteria ${ }^{6}$ in January 1999 and enters into the euro area, its riskless interest rate should be equal to those in the other countries of the monetary union. On the other hand, if the country does not enter into the union, its interest rate will be determined by a variety of factors, including its own monetary policy, and it will generally maintain a positive spread relative to countries in the union. Hence, assuming $I R \_S P R_{t}^{I N}=0$ and $I R_{-} S P R_{t}$ OUT $=\theta>0$ in (16), we can estimate the probability assigned by the financial markets at time $t$ to the event that the country belongs to the euro area by January 1999:

$$
\mathrm{p}_{\mathrm{t}}=1-\mathrm{IR} \_\mathrm{SPR} \mathrm{t}_{\mathrm{t}} / \theta \text {. }
$$

\footnotetext{
5 Extracting market expectations on a given event from asset prices is a question that has attracted a great deal of interest [see Dillen and Edlund (1997), Favero et al. (2000). [See the review essays by Söderlind and Svensson (1997), and Bates (1998)].

${ }^{6}$ To enter into the Eurozone, the Maastricht Treaty indicated that candidates should lower their inflation rate to within $1.5 \%$ of the lowest three in the European Community, push budget deficits below 3\% of GDP, and decrease debt-toGDP ratios to $60 \%$ while maintaining a stable currency.
} 
To estimate (15), we use a more flexible functional form for $p_{t}$ by taking (17) to suggest a negative relationship between the convergence probability and the interest rate spread:

$$
\mathrm{P}_{\mathrm{t}}=\alpha_{0}-\alpha_{1} \mathrm{IR} \_\mathrm{SPR} \text {, }
$$

So that, $\mathrm{p}_{\mathrm{t}}\left(1-\mathrm{p}_{\mathrm{t}}\right)=\left(\alpha_{0}-\alpha_{1} \mathrm{IR} \_\mathrm{SPR} \mathrm{t}_{\mathrm{t}}\right)-\left(\alpha_{0}-\alpha_{1} \mathrm{IR} \_\mathrm{SPR} \mathrm{R}_{\mathrm{t}}\right)^{2}$, and regression equation, where $R P_{t+1}$ is the "ex-post realized risk premium":

$$
\begin{aligned}
& R P_{t+1} \equiv S_{t+1}-f_{t}^{t+1}=\beta_{0}+\beta_{1} I R_{-} S P R_{t}+\beta_{2} I R_{-} S P R_{t}^{2} \\
& -\frac{1}{2} \sigma_{m_{t+1}^{F}}^{2}+\frac{1}{2} \sigma_{m_{t+1}^{D}}^{2}-\frac{1}{2}(1-\gamma)^{2} \sigma_{y_{t+1}^{F}}^{2}+\frac{1}{2}(1-\alpha)^{2} \sigma_{y_{t+1}^{D}}^{D}+(1-\gamma) \sigma_{y_{t+1}^{F} m_{t+1}^{F}}-(1-\alpha) \sigma_{y_{t+1}^{D} m_{t+1}^{D}}+u_{t}
\end{aligned}
$$

with

$$
\beta_{0}=\lambda \alpha_{0}\left(1-\alpha_{0}\right) ; \quad \beta_{1}=-\lambda \alpha_{1}\left(1-2 \alpha_{0}\right) ; \quad \beta_{2}=-\lambda \alpha_{1}^{2} \text {. }
$$

The quadratic polynomial in (IR_SPR) captures the effect on the risk premium of the probability of joining the euro.

The risk premium, expression (19), also includes conditional variances

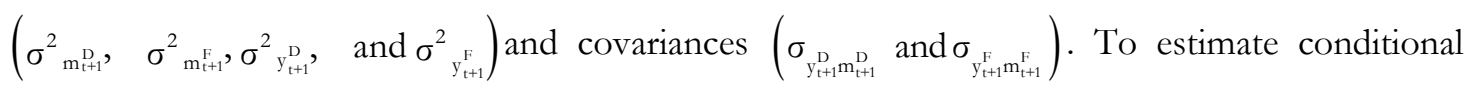
variances and covariances for each country we additionally assume that the dynamics of real and monetary variables, money supply and industrial production can be summarized by a VARMA model in logged differences with GARCH innovations, which allows for some possible nonlinear dependence among them. Appendix 1 shows the specification and estimation of the conditional second order moments.

The unquestionable participation of Germany in the euro area makes it reasonable to focus the analysis on differentials respect to German interest rates. Therefore, the probability of a given country to adopt the single currency from the outset of the Eurozone will be inversely related to the spread of interest rates with Germany. We consider interest rates from swap markets to be more reliable than those from the market for government bonds, which is rather narrow and illiquid in some countries. Furthermore, the tax treatment of returns on public debt differs across countries, while the swap market is very liquid and contracts are standardized across currencies, including the tax treatment of returns, and they are not affected by default risk. Using the spread in 3-year swap rates as a proxy for the probability of convergence is based on our belief that a 3- 
year maturity is more likely to capture expectations of convergence to the euro area for a country. Its behavior is similar to those of the 5 - and 10 -year rates, while the 1 -year rate is influenced by monetary policy decisions.

\section{2.- Accounting for the risk premium}

Interest rate spreads with Germany and risk premium values for France, Spain, and United Kingdom are shown in Figure 1 for the 1994:01-1998:04 period. In all cases, the risk premium series is clearly more volatile than the interest rate spread. Over 1994 and the first part of 1995, the spread increased for Spain, sharply decreasing during 1996, reflecting a growing probability that this country could adopt the single currency from the beginning. There was a transitory increase at the beginning of 1997 and the spread returned very quickly to a decreasing path. The spread with France widened in the spring of 1995 from zero to about 1 percentage point, remaining at that level until the end of 1996, when it fell back to zero. This is consistent with a high probability of this country adopting the single currency from the beginning. On the other hand, the spread showed a positive trend since the beginning of 1994 for the United Kingdom, stabilizing after 1996 but without the sharp decrease observed for Spain and France. These graphs suggest that for Spain and France, an increase in IR_SPR (i.e. a loss in market confidence) induces an increase in the volatility of the risk premium. However, for the United Kingdom, the figure could indicate that this country was not considered to be a likely participant in the euro. Therefore, in this case the correlation between spread and risk premium is more difficult to explain.

We first present in Table 1 least-squares estimates of (19) for the full sample, 1986:021998:04, and for the three bilateral relationships with Germany, without taking into account the effect of the level of uncertainty, so that conditional second order moments for industrial production and money supply are the only explanatory variables. This sample exploits all available data on conditional second order moments. We use risk premium data corrected from extreme values, which sharply decreases the evidence of residual autocorrelation. $\mathrm{R}^{2}$ values are rather low, although estimated parameters show their right sign when significant. However, the overall suggestion is that macroeconomic uncertainty may not be the most important factor determining risk premium in exchange rates.

Alternatively, we analyzed whether the euro-uncertainty can account for the risk premium. Using the longer available sample for interest rate swaps, 1992:02-1998:04, we obtained a poor fit (not shown in the paper), probably because of including the period prior to formal approval of the 
Union Treaty. Convergence criteria were part of the European Union Treaty, which was approved at the European Council celebrated at Maastricht in February 1992. However, their final approval at the level of the Congress of each country took place in November 1993. Hence, even though governments could consider in 1992 the possibility of implementing policy with a goal of achieving convergence, it is just since 1994 that convergence criteria had a formal validity.

When the shorter 1994:01 - 1998:04 period is considered in Table 2, results become much more satisfactory in terms of explanatory power as well as significance and sign of individual coefficients. Simple and adjusted $\mathrm{R}^{2}$ coefficients are between $10 \%$ and $15 \%$, well above their values for the longest sample. The interest rate spread is statistically significant, except for the GBP/GEM relationship, but even there, the estimated coefficient in the spread takes the highest value among the three currencies considered. Lack of significance in this currency may be a consequence of colinearity between the interest rate spread and its squared value, as confirmed by the result of the Wald test for joint significance of both variables. Except for this currency, the coefficients of the quadratic function have the expected sign, suggesting that the linear probability term would not adequately capture all the information regarding the risk premium in that currency. The general conclusion is that it was only after 1994 when the preference uncertainty became a relevant factor in the time evolution of the risk premium for these currencies.

Table 3 presents the estimation results for the full model, including macroeconomic uncertainty and the uncertainty on convergence, over the 1994:01-1998:04 period. Conditional second order moments of fundamental macroeconomic variables are generally not significant. On the contrary, uncertainty on convergence to the Eurozone, as captured by the quadratic function on the interest rate spread, is almost always significant.

We can assess the contribution of macroeconomic uncertainty and euro-uncertainty to the fitted risk premium as shown in Figure 2. The left graph shows, for the 1994:01-1998:04 period, the actual exchange risk premium and the fitted values from the model in Table 3. the middle column shows the part of the fitted risk premium accounted for by macroeconomic uncertainty, $\hat{\beta}_{3} \sigma_{\mathrm{m}+1}^{2}+\hat{\beta}_{4} \sigma_{\mathrm{m}_{\mathrm{t}+1}^{\mathrm{F}}}^{2}+\hat{\beta}_{5} \sigma_{y_{\mathrm{t}+1}^{\mathrm{D}}}^{\mathrm{D}}+\hat{\beta}_{6} \sigma_{y_{\mathrm{t}+1}^{\mathrm{F}}}^{\mathrm{F}}+\hat{\beta}_{7} \sigma_{y_{\mathrm{t}+1}^{\mathrm{D}} \mathrm{m}_{\mathrm{t}+1}^{\mathrm{D}}}^{\mathrm{D}}+\hat{\beta}_{8} \sigma_{\mathrm{y}_{\mathrm{t}+1}^{\mathrm{F}} \mathrm{m}_{\mathrm{t}+1}^{\mathrm{F}}}$, and the right column displays the part of the fitted risk premium accounted for by euro-uncertainty, $\hat{\beta}_{2} I R \_S P R_{t}+\hat{\beta}_{3} I R \_S P R_{t}^{2}$. Figure 3 presents several scatter diagrams for the fitted risk premium versus: ( $($ ) the observed exchange risk premium (left column), (ii) the macroeconomic uncertainty contribution (middle column), and (iii) the euro-uncertainty contribution (right column). An inspection of these diagrams reveals that 
the risk premium is extremely volatile and it is more closely related to the variable measuring the euro-uncertainty than to macroeconomic uncertainty. That is also reflected in the correlations coefficients between each variable with the fitted risk premium, which are noticeably higher for euro uncertainty (between 0.70 and 0.93 ) than for macroeconomic uncertainty (between 0.19 and $0.58)^{7}$

The general conclusion is that the uncertainty on whether the country fulfils the convergence criteria established in the Maastricht agreement is more important when explaining the exchange rate risk premium than the economic fundamentals. This evidence arises only after 1994, suggesting that it was the formal approval of the Maastricht criteria, more than the Maastricht agreement itself, the starting point for exchange rate markets to incorporate the uncertainty on the convergence process in the determination of the risk premium.

We now have all the information needed to estimate from (19) numerical values for the probability attached that the market to the event that each country joins the European monetary union at a given date, as explained in the next section. The probabilities we compute turn out to be very similar to those estimated by the J.P. Morgan EMU calculator.

\subsection{Numerical estimates of convergence probabilities}

From the estimation of (19) in Table 3 we can recover estimates 8 for the probabilities that France, Spain, and UK joined the euro area in April 1999. Estimated probabilities of joining the EMU, normalized so that $p_{t} \in[0,1]$, are shown in Figure 4. The results look fairly reasonable, providing evidence in favour of modelling the probability of convergence as a function of the interest rate spread. For Spain and France the value of the indicator rose since the beginning of 1996. The upward trend suggests the perception of an increased probability that Spain and France would adopt the single currency since the beginning. The United Kingdom had a high probability of entering the Eurozone during late 1993 but it collapsed during the general wave of pessimism on the future of the currency union during 1994. Since then, the probability continuously

\footnotetext{
${ }^{7}$ Even though a precise evaluation of the exact contribution of each component might require a careful treatment of the correlation between them, our analysis clearly favours the greater relevance of euro uncertainty in the determination of the exchange rate risk premium.

8 From the estimation of (19) in Table 3 We can recover estimates for $\alpha_{0}, \alpha_{1}$ and $\lambda$. The system of equations (20) does not have an analytical solution and needs to be solved numerically. Then, from (18) it is straightforward to compute convergence probabilities.
} 
decreased until the end of 1997 suggesting, as it was finally the case, that the likelihood of this country in joining the euro area was not considered to be particularly high.

\section{4.- Conclusions}

We have proposed a general equilibrium model to characterize risk premium in the exchange rate market. The model has as a main feature the state dependency of preferences on the perceived level of uncertainty. As a consequence, the excess return in exchange rates is a function of two factors: i) the volatility of fundamental variables (money and output), and ii) the perception by private agents on the general level of uncertainty in the economy. The stochastic discount factor is then connected to the properties of money, output and a broad uncertainty index, and the presence of the latter increases the sensitivity of the stochastic discount factor to even small variations in consumption. Therefore, our model does not rely as much on consumption risk as more standard models to explain the currency risk premium.

We have shown that the perception by private agents on the level of uncertainty is quantitatively important for reproducing the observed risk premium along the convergence process to the European currency union. Hence, it seems that forces other than those from money and goods markets were important sources of uncertainty during this period, a fact that was reflected in the exchange rate risk premium. A quadratic function of interest rate spreads, used as proxy for the perception of risk, has an acceptable explanatory power in the 1994-1998 period, once national Parliaments approved the Maastricht criteria. Regarding fundamental uncertainty, the relevance of the conditional variances of money supply and industrial production as well as the conditional covariance between these two variables is rather limited, in consistency with results reached by other authors.

Three western European countries in the EMS, United Kingdom, Denmark and Sweden, have not yet adopted the euro. Besides, the European Union has incorporated twelve Eastern European countries as new members, and our model could be used to explain the behavior of exchange rate risk premia in these countries, as they move towards joining the euro. A similar analysis could also be applied if common currency areas in Latin America or South East Asia are eventually approved. 


\section{References:}

Alvarez, F., Atkenson, A., Kehoe, P., 2007. "Time-varying risk, interest rates, and exchange rates in general equilibrium”, Staff Report, Federal Reserve Bank of Minneapolis.

Baba, Y., Engle R., Kraft, D., Kroner, K., 1991. “A multivariate simultaneous generalized ARCH”, Economics Working Paper Series 89-57r, Department of Economics, UC San Diego.

Bates, D., S., 1998. "Financial Markets' assessment of EMU”, paper presented at the CarnegieRochester Conference, November.

Backus, D., Foresi, S., Telmer, C., 2001. "Affine Term Structure Models and the Forward Premium Anomaly". Journal of Finance 56, 1, 279-303.

Bakshi, G., Chen, Z., 1996. "The spirit of capitalism and stock-market prices". American Economic Review 86, 133-157

Bollerslev, T., 1986. "Generalized autoregressive conditional heteroskedasticity", Journal of Econometrics 31, 307-327.

Box, G., Tiao, G., 1975. "Intervention Analysis with applications to economic and environmental problems". Journal of American Statistical Association 70, 70-79.

Campbell, J., Y., Cochrane, J., H., 1999. "By force of habit: a consumption-based explanation of aggregate stock market behaviour”. Journal of Political Economy 107, 205-251.

Campbell J., Viceira, L. 2002. Strategic asset allocation: portfolio choice for long term investors, Oxford University Press Inc. New York.

Constantinides, G. M., 1990. "Habit formation: a resolution of the equity premium puzzle", Journal of Political Economy, 98, 519-543.

Dillén, H., Edlund, M., 1997. "EMU expectations and interest rates". Bank of Sweden, Quarterly Review 2/97.

Engle, R., 1982. "Autoregressive conditional heteroskedasticity with estimates of the variance of U.K inflation”. Econometrica 50, 987-1008.

Fama, E., 1984. "Forward and spot exchange rates", Journal of Monetary Economics, 14, 319-338.

Favero, C. A., Giavazzi, F., Iacone, F., Tabellini, G., 2000. "Extracting Information From Asset Prices: The Methodology of EMU Calculators". European Economic Review, 44, 1607-1632.

$\mathrm{Hu}, \mathrm{X} ., 1997$. "Macroeconomic uncertainty and risk premium in the foreign exchange market", Journal of International Money and Finance, 16, 699-718.

J. P. Morgan, 1997. The EMU calculator handbook, Technical note, London.

Lucas, R. E. Jr., 1982. "Interest rates and currency prices in a two country world", Journal of Monetary Economics, 10, 335-359.

Soderlind, P. Svensson, L. E. O., 1997. "New Techniques to extract market expectations form financial instruments". Discussion paper, $\mathrm{n}^{\circ}$ 1556, CEPR, London, UK. 


\section{Appendix 1-}

\section{Specification and estimation of conditional second order moments}

With regard to fundamental uncertainty we assume, as in $\mathrm{Hu}$ (1992) that, conditional on available information, growth rates in fundamental variables $\left(m_{t+1}^{i}\right.$ and $\left.y_{t+1}^{i} ; i=D, F\right)$ follow a joint lognormal distribution. We assume that the dynamics of real and monetary variables, represented by the money supply and industrial production, can be summarized by a VARMA model in logged differences with GARCH innovations, which allows for possible nonlinear dependence among them. ${ }^{9}$

Standard specification tools ${ }^{10}$ suggest a $\operatorname{VARMA}(1,1)$ model for $\left(\ln \left(m_{t}\right), \ln \left(y_{t}\right)\right)$ for Spain, a VAR(3) for Germany, a VAR (2) with a seasonal VAR(1) component for the UK, and a VAR (3) with a seasonal VAR (2) for France. Evidence of seasonal components shows up in spite of using seasonally adjusted time series data. All these models are special cases of:

$$
\begin{aligned}
& \left.\mathrm{I}+\left[\begin{array}{cc}
\varphi_{11} & \varphi_{12} \\
1 & 1 \\
\varphi_{21} & \varphi_{22}
\end{array}\right] \mathrm{B}+\left[\begin{array}{cc}
\varphi_{11} & \varphi_{12}^{2} \\
2 & 2 \\
\varphi_{21} & \varphi_{22}^{2}
\end{array}\right] \mathrm{B}+\left[\begin{array}{cc}
3 & 3 \\
\varphi_{11} & \varphi_{12} \\
3 & 3 \\
\varphi_{21} & \varphi_{22}
\end{array}\right] \mathrm{B}^{3}\right) \\
& \left(\mathrm{I}+\left[\begin{array}{rr}
\Phi_{1}^{1} & 0 \\
0 & \Phi_{2}^{1}
\end{array}\right] \mathrm{B}{ }^{12}+\left[\begin{array}{rr}
\Phi_{1}^{2} & 0 \\
0 & \Phi_{2}^{2}
\end{array}\right] \mathrm{B} 24\right)\left(\begin{array}{l}
\ln \left(\mathrm{m}_{\mathrm{t}}\right) \\
\ln \left(\mathrm{y}_{\mathrm{t}}\right)
\end{array}\right)=\left[\begin{array}{l}
\lambda_{1} \\
\lambda_{2}
\end{array}\right]+\left(\mathrm{I}+\left[\begin{array}{cc}
\theta_{11}^{1} & \theta_{12}^{1} \\
\theta_{21}^{1} & \theta_{22}^{1}
\end{array}\right] \mathrm{B}\right)\left(\begin{array}{c}
\varepsilon_{\mathrm{m}_{\mathrm{t}}} \\
\varepsilon_{\mathrm{y}_{\mathrm{t}}}
\end{array}\right) \\
& \left(\begin{array}{c}
\varepsilon_{\mathrm{m}_{\mathrm{t}}} \\
\varepsilon_{\mathrm{y}_{\mathrm{t}}}
\end{array}\right) / \mathrm{I}_{\mathrm{t}-1} \sim \mathrm{N}\left(\left(\begin{array}{l}
0 \\
0
\end{array}\right),\left(\begin{array}{cc}
\sigma_{\mathrm{m}_{\mathrm{t}}}^{2} & \sigma_{\mathrm{m}_{\mathrm{t}} \mathrm{y}_{\mathrm{t}}} \\
\sigma_{\mathrm{m}_{\mathrm{t}} \mathrm{y}_{\mathrm{t}}} & \sigma_{\mathrm{y}_{\mathrm{t}}}^{2}
\end{array}\right)\right)
\end{aligned}
$$

with $B$ being the backshift operator, and $\varepsilon_{\mathrm{t}}$ the innovation vector.

As initial conditions, we used estimates obtained under the assumption of lack of heteroskedasticity. Lagrange multiplier and Ljung-Box statistics on the residuals point out to possible conditional heteroskedasticity in the money supply for France and the UK, as well as for an autoregressive structure for the covariance between the money supply and the industrial production in France. These tests led us to specifying a $\operatorname{GARCH}(1,1)$ model for the conditional variances and covariance in (22):

$$
\left[\begin{array}{c}
\sigma_{m_{t}}^{2} \\
\sigma_{m_{t} y_{t}} \\
\sigma_{y_{t}}^{2}
\end{array}\right]=\left[\begin{array}{c}
c_{01} \\
c_{02} \\
c_{03}
\end{array}\right]+\left[\begin{array}{rrr}
a_{11} & 0 & 0 \\
0 & a_{22} & 0 \\
0 & 0 & a_{33}
\end{array}\right]\left[\begin{array}{r}
\varepsilon_{m_{t-1}}^{2} \\
\varepsilon_{m_{t-1}} \varepsilon_{y_{t-1}} \\
\varepsilon_{y_{t-1}}^{2}
\end{array}\right]+\left[\begin{array}{rrr}
g_{11} & 0 & 0 \\
0 & g_{22} & 0 \\
0 & 0 & g_{33}
\end{array}\right]\left[\begin{array}{c}
\sigma_{m_{t-1}}^{2} \\
\sigma_{m_{t-1} y_{t-1}} \\
\sigma_{y_{t}}^{2}
\end{array}\right]
$$

We imposed diagonality constraints, so that $\sigma_{m_{t}}^{2}, \sigma_{y_{t}}^{2}, \sigma_{m_{t} y_{t}}^{2}$ depend only on their own lags and lags of $\varepsilon_{m_{t}}^{2}, \varepsilon_{y_{t}}^{2}, \varepsilon_{m_{t} y_{t}}$, respectively. These restrictions are made to avoid the numerical difficulties that

\footnotetext{
${ }^{9}$ As proposed by Bollerslev (1986) and Baba, Engle, Kraft and Kroner (1991), among many others.

10 Partial and simple autocorrelation functions as well as Akaike, Hannan and Quinn, and Schwarz criteria.
} 
would arise when estimating an over-parametrized model. For estimation, we used an alternative $\operatorname{VARMA}(1,1)$ representation of the GARCH $(1,1)$ model: Let us considerer the $3 \mathrm{x} 1$ stochastic vector:

$$
\xi_{\mathrm{t}}=\operatorname{vech}\left(\varepsilon_{\mathrm{t}} \varepsilon_{\mathrm{t}}^{\prime}\right)-\operatorname{vech} \Sigma_{\mathrm{t}}
$$

where $\operatorname{vech}\left(\varepsilon_{t} \varepsilon_{t}^{\prime}\right)=\left(\varepsilon_{m_{t}}^{2} \varepsilon_{m_{t} y_{t}} \varepsilon_{y_{t}}^{2}\right)^{\prime}, \operatorname{vech} \Sigma_{t}=\left(\sigma_{m_{t}}^{2} \sigma_{m_{t} y_{t}} \sigma_{y_{t}}^{2}\right)^{\prime}$ and $\xi_{t}$ is a white noise process.

Substituting (24) in (23) and rearranging:

$$
\left(\mathrm{I}-\left[\begin{array}{ccc}
\mathrm{a}_{11}+\mathrm{g}_{11} & 0 & 0 \\
0 & \mathrm{a}_{22}+\mathrm{g}_{22} & 0 \\
0 & 0 & \mathrm{a}_{33}+\mathrm{g}_{33}
\end{array}\right] \mathrm{B}\right)\left[\begin{array}{c}
\varepsilon_{\mathrm{m}_{\mathrm{t}}}^{2} \\
\varepsilon_{\mathrm{m}_{\mathrm{t}}} \varepsilon_{\mathrm{y}_{\mathrm{t}}} \\
\varepsilon_{\mathrm{y}_{\mathrm{t}}}^{2}
\end{array}\right]=\left[\begin{array}{c}
\mu_{1} \\
\mu_{2} \\
\mu_{3}
\end{array}\right]+\left(\left[\begin{array}{rrr}
g_{11} & 0 & 0 \\
0 & g_{22} & 0 \\
0 & 0 & g_{33}
\end{array}\right] \text { B)( } \begin{array}{c}
\xi_{\mathrm{m}_{\mathrm{t}}} \\
\xi_{\mathrm{m}_{\mathrm{t}} \mathrm{y}_{\mathrm{t}}} \\
\xi_{\mathrm{y}_{\mathrm{t}}}
\end{array}\right)
$$

in which the presence of the sum $a_{\mathrm{ii}}+\mathrm{g}_{\mathrm{ii}}$ allows us to test for stationarity in variance, whenever $\left|\mathrm{a}_{\mathrm{ii}}+\mathrm{g}_{\mathrm{ii}}\right|<1$ [Bollerslev (1986)].

In the estimated models (not shown in the paper), conditional variances for the money supply and the industrial production actually depend on their own innovations, while their conditional covariance depends on innovations in both variables. Conditional heteroskedasticity seems to be present in all countries. As suggested by the previous tests, we estimated heteroskedastic effects for the money supply in France and the UK and the covariance between the money supply and the industrial production in France. We also obtained a statistically significant autoregressive structure for the conditional covariance between both variables in Spain and Germany. No conditional heteroskedasticity in the variances of the money supply or the industrial production was found for these two countries. 


\section{Appendix 2}

Table 1

Least squares estimation of the risk premium associated to macroeconomic uncertainty. Full sample: 1986:02-1998:04 (a)(b) (c)

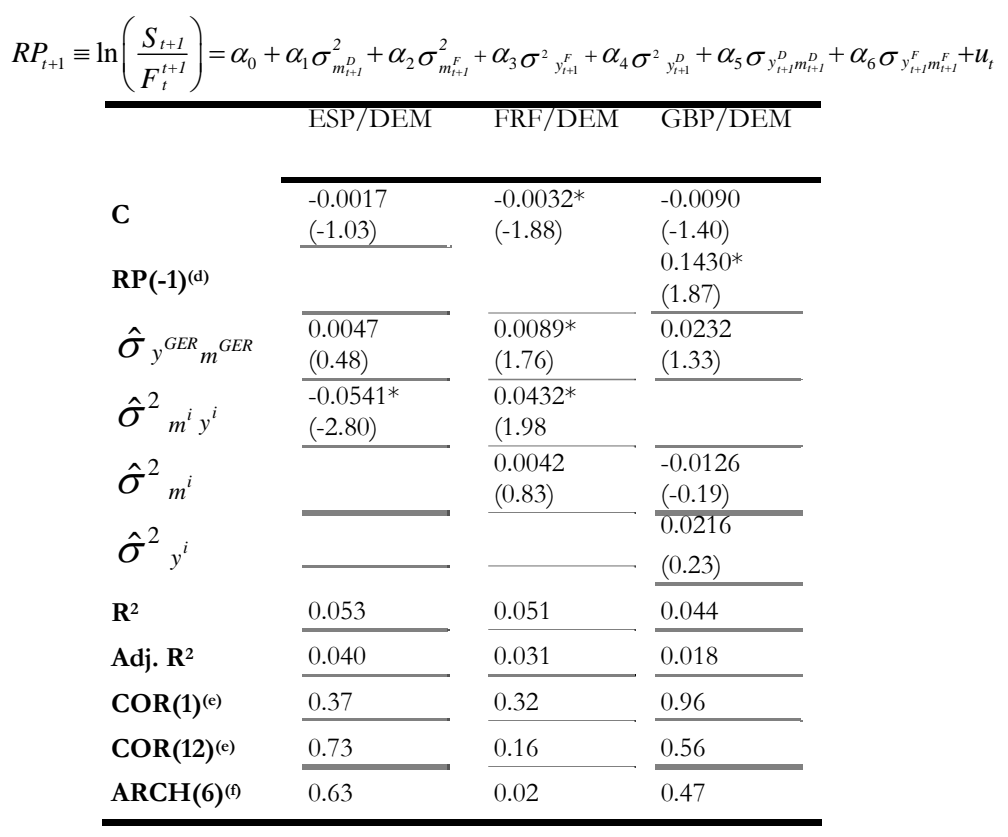

Notes:

(a) T-statistics in parentheses.

(b) $\quad \hat{\sigma}_{x^{D C}}^{2} \equiv \operatorname{var}_{t}\left(\log \left(x_{t+1}^{i}\right)\right) \sigma_{x_{t+1}^{i} p_{t+1}^{i}} \equiv \operatorname{cov}_{t}\left(\log \left(x_{t+1}^{i}\right) \log \left(p_{t+1}^{i}\right)\right)$ for $\mathrm{i}=\mathrm{FR}, \mathrm{SP}, \mathrm{UK}$

(c) An asterisk denotes a coefficient significant at the $10 \%$ level

(d) $\mathrm{RP}(-1)$ denotes the lagged risk premium

(e) $P$-value of Breusch-Godfrey test statistic for residual serial correlation up to lag order $p$.

(f) Autoregressive conditional heteroskedasticity test. $\mathrm{ARCH}(6)$ is the p-value of $\mathrm{LM}$ test statistic.

Table $2^{(a)}$

Least squares estimation of the risk premium associated to euro-uncertainty.

Sample: 1994:01-1998:04

$R P_{t+1}=\gamma_{0}+\gamma_{1} I R_{-} S P R_{t}+\gamma_{2} I R_{-} S P R 2_{t}+u_{t}$

\begin{tabular}{|c|c|c|c|}
\hline & ESP/DEM & FRF/DEM & GBP/DEM \\
\hline C & $\begin{array}{l}-0.0061^{*} \\
(-1.83)\end{array}$ & $\begin{array}{l}-0.0016 \\
(-1.46)\end{array}$ & $\begin{array}{l}0.0242 \\
(1.25)\end{array}$ \\
\hline$I R \_S P R$ & $\begin{array}{l}0.4651 * \\
(1.81)\end{array}$ & $\begin{array}{l}0.8758^{*} \\
(1.87)\end{array}$ & $\begin{array}{l}-1.5313 \\
(-0.80) \\
\end{array}$ \\
\hline$I R \_S P R 2$ & $\begin{array}{l}-10.017^{*} \\
(-2.33)\end{array}$ & $\begin{array}{l}-101.11^{*} \\
(-2.84)\end{array}$ & $\begin{array}{l}6.3577 \\
(0.13)\end{array}$ \\
\hline Euro-Uncertainty ${ }^{(\mathrm{b})}$ & 0.022 & 0.002 & 0.022 \\
\hline $\mathbf{R}^{2}$ & 0.144 & 0.223 & 0.144 \\
\hline Adj. $\mathbf{R}^{2}$ & 0.109 & 0.192 & 0.109 \\
\hline $\operatorname{COR}(1)^{(\mathrm{c})}$ & 0.87 & 0.24 & 0.53 \\
\hline $\operatorname{COR}(12)^{(\mathrm{e})}$ & 0.90 & 0.59 & 0.30 \\
\hline $\operatorname{ARCH}(6)^{(d)}$ & 0.16 & 0.64 & 0.57 \\
\hline
\end{tabular}

Notes:

(a) T-statistics in parentheses.

(b) P-value for F-statistic for the null hypothesis: $\mathrm{H}_{0}: \gamma_{1}=\gamma_{2}=0$.

(c) $P$-value for Breusch-Godfrey test statistic for residual serial correlation up to lag order $p$, in brackets.

(d) Autoregressive conditional heteroskedasticity test. $A R C H(6)$ is the p-value of $\mathrm{LM}$ test statistic for an ARCH structure of order 6.

(e) An asterisk denotes a coefficient significant at the $10 \%$ level 
Table 3

Least squares estimation of the risk premium equation ${ }^{(a)}$

Sample: 1994:01-1998:04

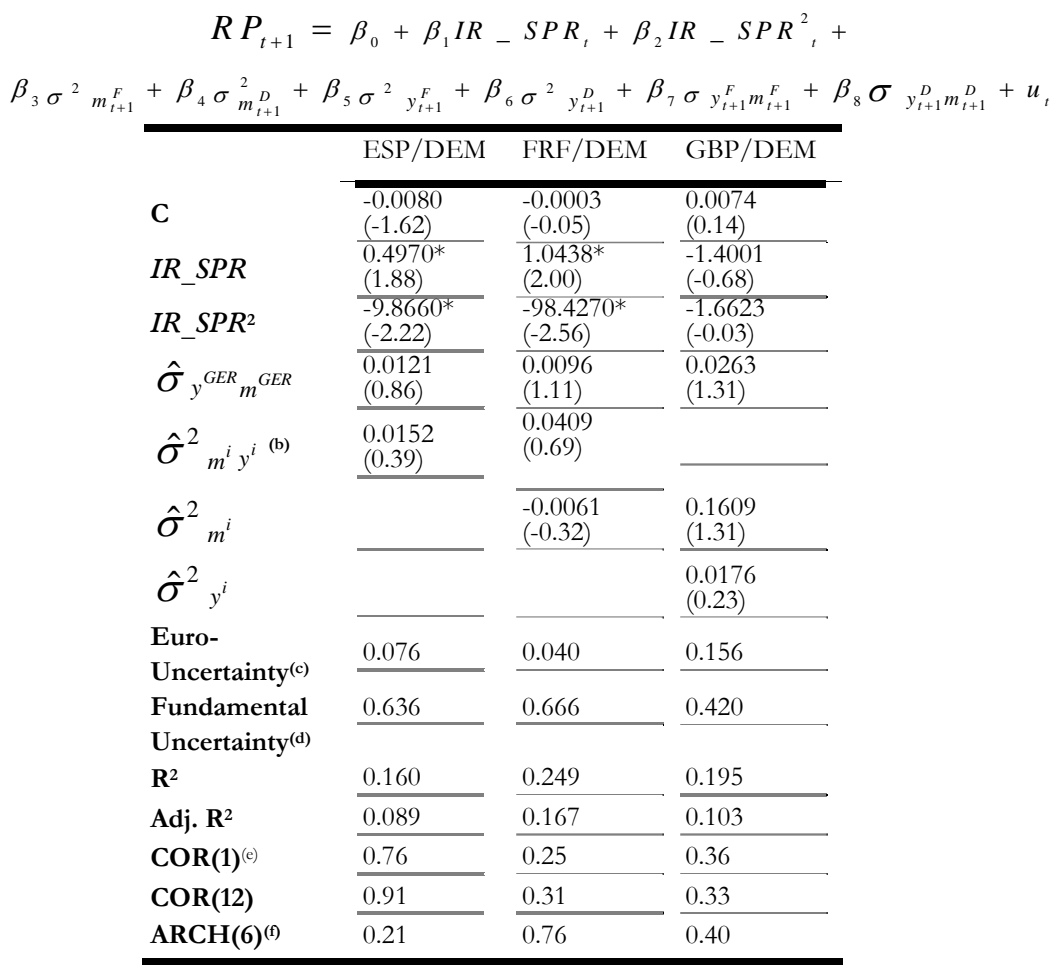

Notes:

(a) t-statistics in parentheses.

(b) $\hat{\sigma}_{x^{\prime}}^{2} \equiv \operatorname{var}_{t}\left(\log \left(x_{t+1}^{i}\right)\right) \sigma_{x_{t+1}^{i} p_{t+1}^{i}} \equiv \operatorname{cov}_{t}\left(\log \left(x_{t+1}^{i}\right) \log \left(p_{t+1}^{i}\right)\right)$ for $\mathrm{i}=\mathrm{FR}, \mathrm{SP}, \mathrm{UK}$

(c) P-value for F-statistic for the null hypothesis: $\mathrm{H}_{0}: \beta_{1}=\beta_{2}=0$.

(d) P-value for F-statistic for the null hypothesis: $H_{0}: \beta_{3}=\beta_{4}=\beta_{5}=\beta_{6}=\beta_{7}=\beta_{8}=0$.

(e) $P$-value of Breusch-Godfrey test statistic for residual serial correlation up to lag order $p$, in brackets.

(f) Autoregressive conditional heteroskedasticity test. $\mathrm{ARCH}(6)$ is the p-value of LM test statistic for an ARCH structure of order 6.

(g) An asterisk denotes a coefficient significant at the $10 \%$ level 
Figure 1

Interest rate swap spreads (IR_SPR) and observed risk premium $\left(R P_{t+1}\right)$

Sample: 1994:01-1998:04

- $\mathrm{RP}(\mathrm{ESP} / \mathrm{DEM}) \quad$ - IR_SPR (SP)

- $\mathrm{RP}(\mathrm{FR} / \mathrm{DEM}) \quad$ - IR_SPR (FR)

- $\mathrm{RP}(\mathrm{GPB} / \mathrm{DEM}) \quad$ - IR_SPR (UK).
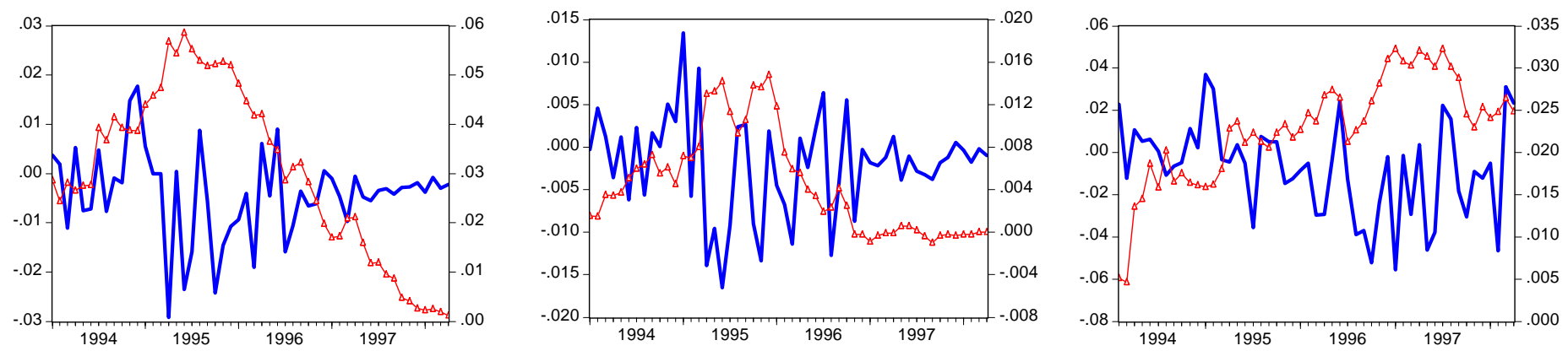
Figure 2

Observed risk premium vs. fitted risk premium, macroeconomic and euro-uncertainty ${ }^{(\mathrm{a})(\mathrm{b})(\mathrm{c})}$ Sample: 1994:01-1998:04

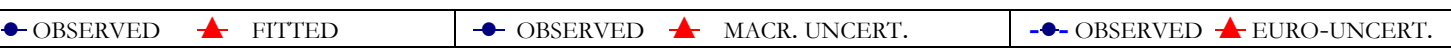

ESP/DEM
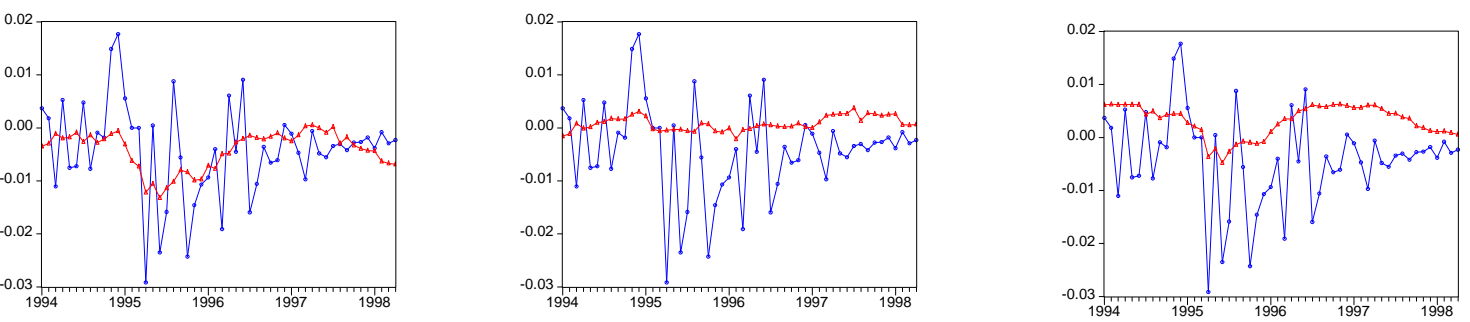

FRF/DEM
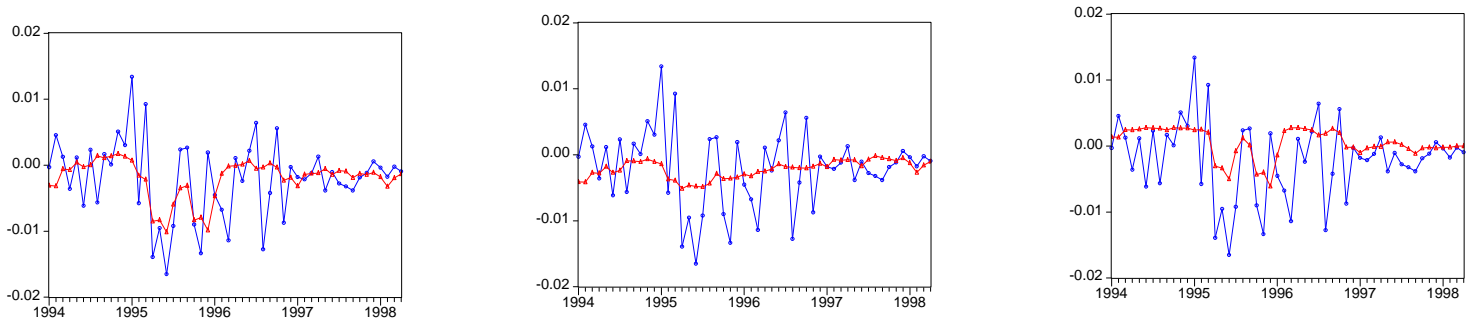

GBP/DEM
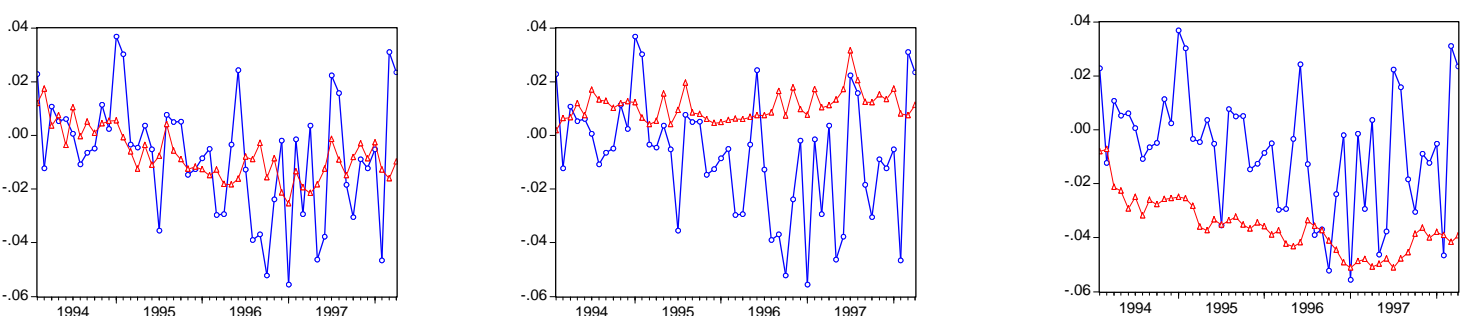

Notes:

(a) Left column: Observed exchange risk premium versus the fitted value from the model in Table 4

(b) Middle column: Observed exchange risk premium versus macroeconomic uncertainty contribution

(c) Right column: Observed exchange risk premium versus EURO-uncertainty contribution 
Figure 3

Scatter diagrams: fitted risk premium (horizontal axis) vs. observed risk premium, macroeconomic and euro uncertainty contribution ${ }^{(\mathrm{a})(\mathrm{b})(\mathrm{c})}$.

Sample: 1994:01-1998:04

\begin{tabular}{|ll|ll|ll|}
\hline FITTED VS. OBSERVED & FITTED & VS. MACR. UNCERT. & FITTED VS. EURO-UNCERT. \\
\hline
\end{tabular}

ESP/DEM
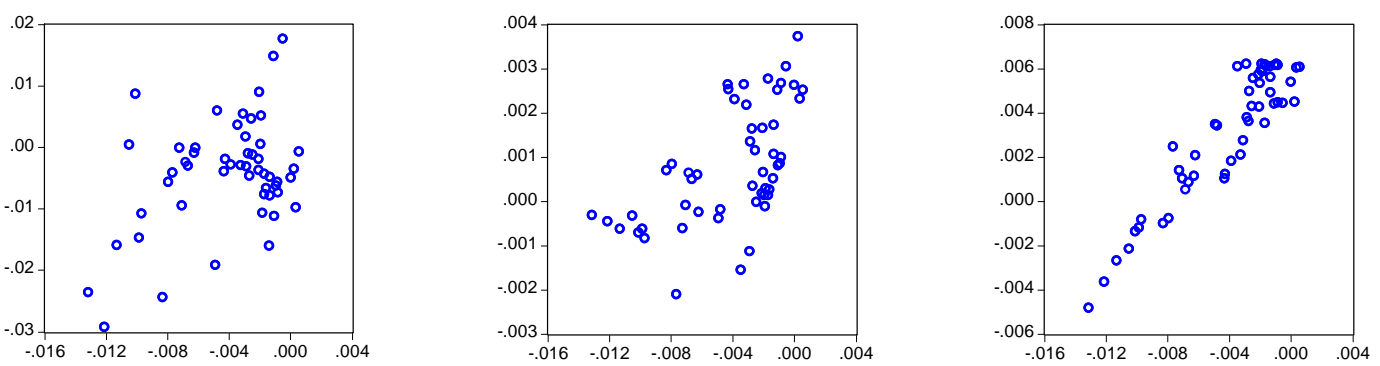

Correlation $^{(\mathrm{d})}$
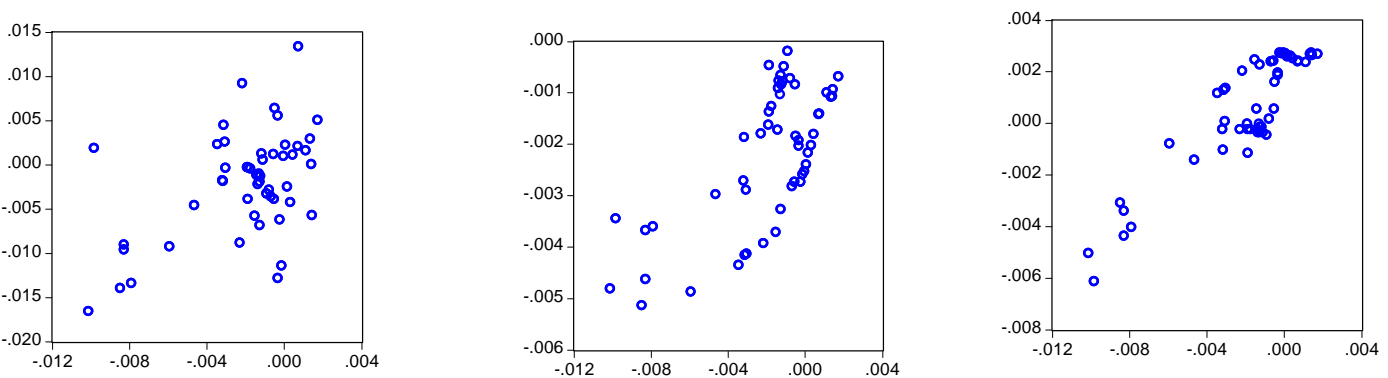

GBP/DEM
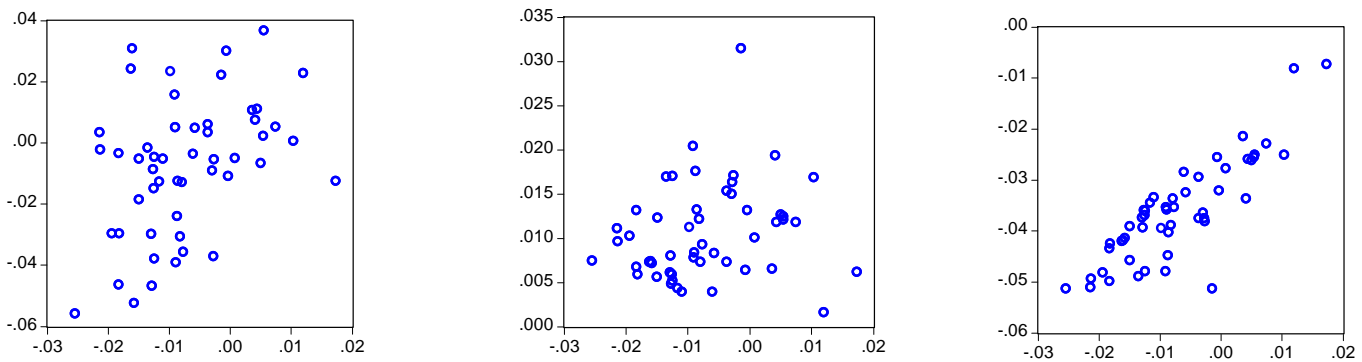

Notes:

(a) Left column: observed risk premium versus the fitted risk premium from the model in Table 4

(b) Middle column: Macroeconomic uncertainty contribution versus the fitted risk premium

(c) Right column: EURO-uncertainty contribution versus the fitted risk premium

(d) Correlation between variables in scatter diagrams 
Figure 4

Probability indicator for Spain, France and the United Kingdom Sample: 1994:01-1998:04
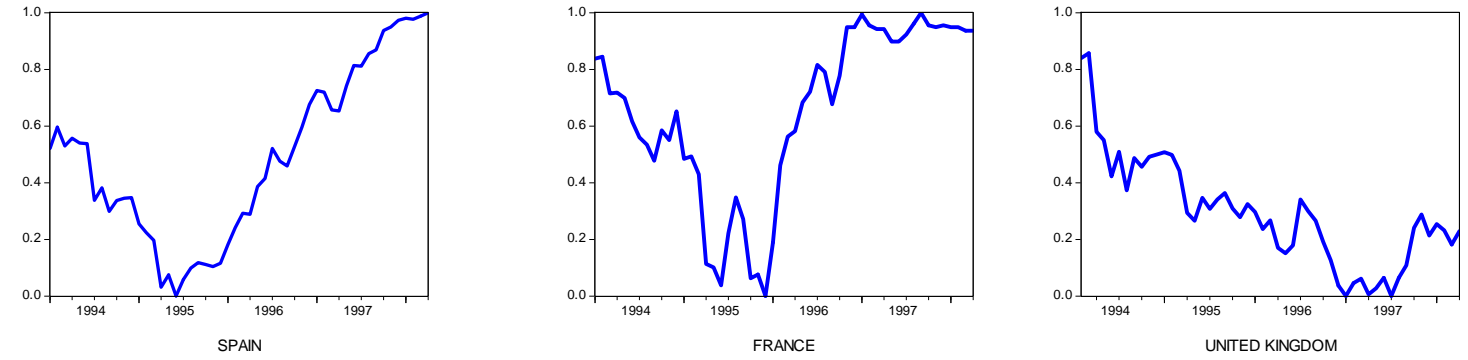